Научная статья

УДК 34.09

DOI 10.25205/2542-0410-2021-17-4-5-14

\author{
Правовое регулирование \\ постановки нравственного воспитания учащихся \\ в учебных заведениях Российской империи \\ второй половины XIX - начала XX века
}

\author{
Оксана Владимировна Ищенко \\ Сургутский государственный университет \\ Сургут, Россия \\ iovfu@yandex.ru, https://orcid.org/0000-0001-9761-6204
}

Аннотация

Анализируются правовые основания, комплекс источников и юридических средств осуществления нравственного воспитания в школах Российской империи второй половины XIX - начала XX в. Представлены основные законодательные акты - уставы, правила и циркуляры, определявшие регулирование воспитательной работы в школе на общегосударственном, учебно-окружном и локальном уровнях. Сделан вывод о том, что волей законодателя закреплены целевые установки нравственного воспитания учащихся, пределы власти ответственных субъектов и регламентированы основные направления воспитательной работы. Вместе с тем циркулярные распоряжения Министерства народного просвещения не всегда содержали механизм достижения цели, передавая этот вопрос на уровень учебно-окружного начальства и руководства отдельных учебных заведений, что в целом существенно снижало эффективность реализации законодательства в этой сфере.

Ключевые слова

Российская империя, нравственное воспитание, учебные заведения, учащиеся, правовое регулирование, законодательные акты, циркуляры

Для циттирования

Ищенко О. В. Правовое регулирование постановки нравственного воспитания учащихся в учебных заведениях Российской империи второй половины XIX - начала XX века // Юридическая наука и практика. 2021. Т. 17, № 4. C. 5-14. DOI 10.25205/2542-0410-2021-17-4-5-14

\title{
Legal Regulation of the Setting of Moral Education of Students in Educational Institutions of the Russian Empire in the Second Half of $19^{\text {th }}-$ Early $20^{\text {th }}$ Century
}

\author{
Oksana V. Ishchenko \\ Surgut State University \\ Surgut, Russian Federation \\ iovfu@yandex.ru, https://orcid.org/0000-0001-9761-6204
}

Abstract

The article considers the legal grounds, a set of sources and legal means for setting moral education in the schools of the Russian Empire in the second half of the $19^{\text {th }}$ - early $20^{\text {th }}$ centuries. The author of the article analyzes the main legislative acts - charters, rules and circulars, which determined the regulation of educational work in schools at the 
national, educational-district and local levels. The author concludes that the will of the legislator fixed the target settings of moral education of students, the limits of the power of responsible subjects and regulated the main directions of educational work. However, the circular orders of the Ministry of Public Education did not always contain a mechanism for achieving the goal, transferring this issue to the level of the educational district authorities and the management of individual educational institutions. It significantly reduced the effectiveness of the implementation of legislation in this area.

Keywords

The Russian Empire, moral education, educational institutions, students, legal regulation, legislative acts, circulars For citation

Ishchenko O. V. Legal Regulation of the Setting of Moral Education of Students in Educational Institutions of the Russian Empire in the Second Half of $19^{\text {th }}-$ Early $20^{\text {th }}$ Century. Juridical Science and Practice, 2021, vol. 17, no. 4, pp. 5-14. (in Russ.) DOI 10.25205/2542-0410-2021-17-4-5-14

Вторая половина XIX в. в России стала периодом значительных изменений во многих сферах жизни общества и усиления государственного воздействия на развитие сферы образования. Рост промышленного производства, развитие транспортной сети, необходимость усиления обороноспособности страны и конкурентоспособности ее товаров на международной арене - все эти факторы в совокупности требовали притока грамотных специалистов, поэтому в пореформенный период в стране сложилась сеть образовательных учреждений, увеличилось количество учебных заведений и число учащихся в них. При этом государство, понимая школу как один из главных институтов социализации подрастающего поколения, ставило перед ней не только образовательные, но и воспитательные задачи, направленные на формирование нравственности учащихся как неотъемлемой стороны личности, обеспечивающей добровольное соблюдение ею существующих норм, правил, принципов поведения $[1$, c. 10]. Отсюда вытекала направленность воспитательной деятельности школы на формирование личности патриотичной, богобоязненной, высоконравственной, преданной «царю и Отечеству» [2, с. 179]. Определение основных направлений государственной политики в этом вопросе требовало соответствующего правового регулирования, тем более что в условиях имперской формы государственного устройства крайне сложной представлялась реализация нормативных установлений разнопорядковой иерархичной системой государственных институтов относительно различных регионов России [3].

Основными законодательными актами в системе образования Российской империи второй половины XIX - начала XX в. были законы, циркуляры, инструкции и правила, разъяснявшие вопросы практического применения законодательства или дававшие конкретные указания о действиях учебного начальства. Самым массовым видом нормативных документов были циркулярные распоряжения министерства народного просвещения, рассылавшиеся в учебные округа $[4$, c. 41$]$. Циркуляры представляли собой акты распорядительного характера в рамках реализации министерством своей подзаконной нормотворческой компетенции и содержали обязательные правовые предписания, обращенные к подчиненным лицам и подведомственным учреждениям [5, с. 210]. К иным актам, регулирующим правовое пространство деятельности учебных заведений, относились инструкции, правила, уставы [6, с. 47]. Уставами утверждались главные цели воспитания, которые дополнялись и конкретизировались в выпускаемых Министерством народного просвещения рекомендациях, инструкциях и правилах [7, с. 42].

Механизм доведения правительственных распоряжений до уровня конкретных образовательных учреждений чаще всего был достаточно стандартным. Полученные попечителями учебных округов циркулярные распоряжения и другие нормативные документы Министерства народного просвещения изучались на уровне учебно-окружного руководства. На их основе попечителем учебного округа разрабатывались собственные циркуляры, которые вместе с министерскими рассылались затем во все подведомственные учебные заведения. Далее руководство учебных заведений и педагогические советы разрабатывали собственные правила и распоряжения, носившие локальный характер, при этом, как и в современной России, локальные нормативные акты исходили из законов и иных правовых актов централизованного 
регулирования и не могли противоречить им [8, с. 290]. Таким образом, основные нормативные документы, определявшие постановку образовательной и воспитательной работы в школе, формировались на нескольких уровнях: общегосударственном, учебно-окружном и уровне самого учебного заведения.

Одним из главных документов, регламентировавших вопросы образования и воспитания учащихся в пореформенный период, стал утвержденный Министерством народного просвещения в 1871 г. Устав гимназий и прогимназий. Гимназии в нем были определены как заведения, дающие общее образование «воспитывающемуся в них юношеству», что соответствовало идее министра народного просвещения Д. А. Толстого о совмещении научно-образовательной и нравственно-воспитательной задач школы [9, с. 126]. Для реализации воспитательных целей Уставом предусматривалось закрепление за каждым классом в качестве наставника учителя, ведущего в нем уроки. Классные наставники в этом документе определялись как «ближайшие помощники директора и инспектора в наблюдении за успехами и нравственностью учеников вверенных каждому из них классов» ${ }^{1}$.

Согласно выпущенной в 1877 г. Инструкции для классных наставников гимназий и прогимназий ведомства Министерства народного просвещения, классные наставники должны были следить за посещением учениками уроков, их поведением, успеваемостью, руководить выбором книг для чтения, разъяснять ученикам их обязанности, но главное «своим примером, строго рассчитанным и целесообразным применением воспитательных и дисциплинарных мер... содействовать как искоренению во вверенных им учениках дурных привычек и наклонностей, так и пробуждению и укреплению в них чувства правды, чести, уважения к закону и исполнителям его, привязанности к Государю и отечеству и в особенности чувства религиозного» ${ }^{2}$.

В дальнейшем для организации работы классных наставников Министерство народного просвещения выпустило целую серию циркуляров-инструкций. В частности, в циркуляре от 26 июля 1884 г. указывалось на необходимость усиления воспитания у школьников верноподданнических чувств и религиозности $[10$, с. 24]. Все эти положения дублировались и в локальных нормативных документах. Так, в инструкции учителям училищ Сибирского казачьего войска (1913 г.) указывалось, что учитель «воспитывает в детях веру в Бога, любовь и преданность царю и Родине, уважение и почтительность к старшим и друг другу» ${ }^{3}$.

Другим важным документом, регулирующим вопросы нравственного воспитания учащихся, являлись обращенные уже непосредственно к ним Правила для учеников гимназий и прогимназий, утвержденные министром народного просвещения 4 мая 1874 г. Правила имели преамбулу, определяющую цель их введения следующим образом: «Ученики гимназий и прогимназий должны постоянно иметь в виду цель учения... выраженную в словах молитвы пред учением - “возрасти” (умственно и нравственно) “Создателю нашему во славу, родителям же нашим на утешение, Церкви и Отечеству на пользу”» ${ }^{4}$. Для достижения столь высокой цели учащимся давались «к непременному руководству» восемь разделов, охватывавших все стороны ученической жизни: от организации учебы до квартир для проживания. Каждый из этих разделов включал в себя нравственную составляющую.

Первое место в этом списке занимали правила относительно исполнения религиозных обязанностей. Ученикам предписывалось посещать богослужения в воскресные и празднич-

\footnotetext{
${ }^{1}$ Устав гимназий и прогимназий ведомства Министерства народного просвещения 1871 года // Сборник постановлений по Министерству народного просвещения. СПб.: Тип. Т-ва «Общественная польза», 1877. Т. 5. С. 431464.

2 Инструкция для классных наставников гимназий и прогимназий ведомства МНП (Утверждена г. Мин. нар. просв. 5 августа 1877 г.) // Сборник постановлений и распоряжений по гимназиям и прогимназиям ведомства Министерства народного просвещения. 2-е изд. СПб., 1888. С. 36-41.

${ }^{3}$ ИсА. Ф. 54. Оп. 1. Д. 65. Л. 30-31.

${ }^{4}$ Правила для учеников гимназий и прогимназий ведомства Министерства народного просвещения (Утверждены г. министром народного просвещения 4-го мая 1874 г.) // Сборник постановлений и распоряжений по гимназиям и прогимназиям ведомства Министерства народного просвещения. 2-е изд. СПб., 1888. С. 149-159.
} 
ные дни, ежегодно бывать у исповеди и причастия, предоставив свидетельство об этом от своего духовника, если они исполняли «эти христианские обязанности вне прямого надзора и наблюдения учебного начальства». Второй раздел Правил требовал от школьников примерного поведения в учебное время: внимательного выслушивания объяснений учителя, соблюдения строгой дисциплины на уроке, добросовестной подготовки к занятиям и пр., т. е. всего того, что, по мнению властей, способствовало формированию нравственной личности.

Третий раздел содержал правила по отношению к начальникам и наставникам, которым нужно было «беспрекословно повиноваться» и «оказывать всякое почтение... избегая всякого лицемерия, притворства, лжи и обмана». В четвертом разделе, содержащем обязанности учеников по отношению друг к другу, вопросы нравственности занимали основное место. По отношению к своим товарищам ученики должны были быть «вежливы, доброжелательны и дружелюбны». Строго запрещались ссоры, брань и драки между учениками, но еще строже запрещалось «злоупотребление силою против слабейших и, в особенности, против новичков». От учеников требовалось не использовать в разговоре неприличные слова, а «всякого рода неблагопристойные разговоры и рассказы и всякое сообщение или действие, противное нравственной чистоте и клонящееся к соблазну для товарищей», наказывалось вплоть до исключения из учебного заведения. Для сохранения здоровья и успешности учения учащимся предписывалось избегать в учебные дни развлечений и увеселений. «Безусловно воспрещалось» посещение театров, «в коих обыкновенно даются пьесы сомнительного нравственного содержания», так же «безусловно и строжайше» учащимся запрещалось посещать «маскарады, клубы, трактиры, кофейни, кондитерские, бильярдные и другие подобные заведения, а равно и всякого рода публичные и увеселительные места, посещение коих будет признано опасным или неприличным для учеников со стороны ближайшего их начальства» ${ }^{5}$.

Отдельный раздел правил был посвящен вопросам соблюдения учениками порядка и приличия вне стен учебного заведения. Правила предусматривали обязательное ношение формы, обеспечивающей строгость поведения учеников и зрительное их выделение в социальной среде. Излишние украшения и предметы роскоши запрещались. Вне стен школы ученики обязывались вести себя скромно, «соблюдая порядок, благоприличие и вежливость и не причиняя никому никакого беспокойства» ${ }^{6}$.

Заключительный и самый большой раздел Правил был посвящен характеристике ученических квартир и правил поведения на них. Ученики, не имевшие родных в городе учебы, должны были размещаться на одной из рекомендованных учебным начальством и обеспеченных «нравственным надзором» квартир. При наличии на одной квартире больше 15 учеников, им назначался воспитатель. На квартирах с малым количеством проживающих учеников назначались дежурные из старшеклассников, «известных своею доброю нравственностью и хорошими успехами». В Правилах отмечалось: «Если вообще желательно, чтобы каждый добронравный воспитанник гимназии воздействовал на товарищей своим примерным поведением, то понятно, что это самое составляет уже прямую и непременную обязанность тех лучших воспитанников, которым с этой именно целью поручаются для наблюдения известные ученические квартиры и которые поэтому обязаны, по мере своих сил, содействовать нравственному и умственному преуспеянию своих младших товарищей» ${ }^{7}$. Таким образом, главной обязанностью дежурного было наблюдение за нравственностью учеников своей квартиры и за точным исполнением ими всех правил, касающихся квартирной и вообее внегимназической жизни.

Исследователи считают, что в Правилах для учеников гимназий и прогимназий ведомства Министерства народного просвещения 1874 г. к правам школьников относилось только

\footnotetext{
5 Правила для учеников гимназий и прогимназий ведомства Министерства народного просвещения (Утверждены г. министром народного просвещения 4-го мая 1874 г.).

6 Там же.

7 Там же.
} 
«право выбирать книги в библиотеках по своему желанию», все остальное представляли собой обязанности $[6$, с. 52]. Однако в данном случае очевидно стремление авторов документа разработать некий идеальный образ ученика, следуя которому учащиеся воспримут данные обязанности как естественные нормы поведения и будут всегда им следовать.

Нарушение учениками любого пункта установленных правил поведения влекло за собой наказание, предусмотренное Правилами о взысканиях, утвержденными министром народного просвещения 4-го мая 1874 г. Главной целью их введения было нравственное исправление учеников, осуществляемое при применении широкого спектра наказаний, варьировавшегося от выговора и оставления после уроков до заключения в карцер и исключения ${ }^{8}$.

Все утвержденные Министерством народного просвещения правила представляли собой типовые положения, на основе которых учебные заведения разрабатывали свои нормативные акты. Они включали в себя те же разделы, но с определенными дополнениями. Например, согласно Правилам для учащихся Омского землемерного училища, его воспитанники обязаны были носить форму как в стенах учебного заведения, так и вне его, поскольку, как отмечалось педагогическим советом училища, форма «дисциплинирует молодежь, служит для них регулятором границ дозволенного и благопристойного» ${ }^{9}$. Педагогическим советом Барнаульской женской гимназии в 1913 г. были выработаны правила поведения учениц, допускавшие посещение кинематографа, театров, цирка, вечеров и лекций только с разрешения начальницы гимназии, прогулки по улице и посещение катка разрешались в определенные часы, а посещение маскарадов «безусловно не допускалось» ${ }^{10}$. Введение подобных правил производилось также на основе циркулярных положений учебно-окружного начальства. Например, циркуляром Главного инспектора училищ Восточной Сибири от 20 января 1903 г. учащимся было запрещено посещение общественных собраний, а посещение публичных чтений было возможно только при наличии разрешения генерал-губернатора края ${ }^{11}$.

При корректировке основных положений правительственного курса, направленных на формирование нравственности учащихся, любое нормативное решение министерства имело правовое и фактическое основание для его принятия. Правовым основанием могло быть распоряжение высших органов либо законодательно закрепленное правомочие министерства на «самостоятельное соображение» [5, с. 211]. В силу этого, например, в ходе революции 19051907 гг. циркулярные распоряжения Министерства народного просвещения напрямую вытекали из содержания циркуляров главы правительства или циркуляров правоохранительных ведомств. Вопросы нравственного воспитания учащихся были практически заменены запретом их участия в общественной деятельности. Учителям вменялось в обязанность усилить надзор за учащимися, поскольку в циркуляре председателя совета министров П. А. Столыпина от 15 сентября 1906 г. указывалось, что учителя, «не относясь формально к своим обязанностям, должны следить за своими питомцами и вне стен учебных заведений» ${ }^{12}$. Введенный в правительственном циркуляре от 21 января 1906 г. запрет на устройство публичных и противоправительственных митингов, в том числе и в учебных заведениях ${ }^{13}$, был продублирован циркулярным распоряжением министра народного просвещения от 15 ноября 1906 г., запрещавшим сходки и собрания учащихся средних учебных заведений, а также любые ученические организации ${ }^{14}$.

Фактическим основанием для принятия министерского решения являлась сложившаяся во вверенной министерству сфере управления ситуация, требующая разрешения. В основу выбора средств и способов правовой регламентации могла лечь информация, специально соби-

\footnotetext{
${ }^{8}$ Правила о взысканиях (Утверждены г. министром народного просвещения 4-го мая 1874 г.) // Правила для учеников гимназий и прогимназий ведомства Министерства народного просвещения. Казань, 1874. С. $20-44$.

${ }^{9}$ ИсА. Ф. 64. ОП. 1. Д. 1. Л. 45.

${ }^{10}$ ГААК. Ф. 36. Оп. 1. Д. 40. Л. 41.

${ }^{11}$ ГАИО. Ф. 124. Оп. 1. Д. 236. Л. 2.

${ }^{12}$ ИсА. Ф. 270. Оп. 1. Д. 11. Л. 12.

${ }^{13}$ Там же. Д. 13. Л. 7.

${ }^{14}$ ГАТюмО. Ф. И-57. Оп. 1. Д. 38. Л. 2.
} 
раемая из прессы, от граждан, а также в обязательном порядке от подчиненных министерству «мест» [5, с. 212]. Ярким примером наличия такого фактического основания для усиления внимания к вопросам правового регулирования нравственности учащихся стала развернувшаяся в 1907-1908 гг. волна слухов о существовании в ученической среде обществ развратного характера.

Первые сведения о существовании среди учащихся кружков аморальной направленности появились в марте 1907 г., когда в промонархической газете «Орловская речь» были напечатаны заметки о том, что в Орле существует тайное общество в составе гимназистов и гимназисток города, которые на своих сборищах «пьянством умерщвляли дух, а затем занимались возрождением плоти». В это же время статьи схожего содержания появились в газетах г. Перми, а позже Минска, Полтавы, Киева. Заметки вызвали огромный общественный резонанс. Никаких реальных доказательств при проведении тщательного расследования получено не было, но наличие коллективных страхов за судьбу «погибающей молодежи» стало питательной почвой для формирования подобных мифологем [11, с. 97-99].

На основе информации, появившейся в прессе, 14 июля 1908 г. был издан Циркуляр Департамента полиции, в котором отмечалось, что опубликованные сведения о возникновении среди учащихся в средних учебных заведениях различных противонравственных организаций типа «Общества огарков», «Лиги свободной любви» и т. п. сильно преувеличены, но «действительность, к сожалению, не оставляет сомнений в том, что в течение двух-трех последних лет в среде учащейся молодежи обоего пола замечается как общее явление сильный упадок нравственности, выражающийся не только в несоответственном поведении на улицах и в публичных собраниях, но и в крайней доступности развращающим влияниям». Причины сложившейся ситуации, по мнению правоохранительного ведомства, крылись «с одной стороны, в... дезорганизации средней школы, слабости или отсутствии родительского авторитета и отсутствии внешкольного надзора за учащимися и вытекающей отсюда свободой... жизни на частных ученических квартирах... посещении спектаклей, танцевальных вечеров, кинематографа, злоупотребление спиртными напитками и т. п., а с другой - в общей распущенности нравов, являющейся результатом только что пережитого страной революционного периода, вызвавшего появление и массы литературы сначала революционной, направленной к поколебанию государства и авторитета властей, затем порнографической, рассчитанной на удовлетворение низменных инстинктов и потому привлекательной для юношества, только что вырвавшегося на свободу. К этому в качестве причин, оказывающих развращающее влияние на молодежь, надлежит добавить постановку близких к цинизму театральных пьес и скабрезного характера зрелищ, кинематографа, появление соблазнительного содержания открытых писем и т. п.» ${ }^{15}$. Вполне очевидно, что указанный набор причин явного или выдуманного упадка нравственности учащейся молодежи крылся, по мнению правительства, в неисполнении основных правил и инструкций, разработанных для учащихся.

Как преодолеть эту ситуацию, циркуляр не указывал, говоря только о том, что «описанное положение вещей обязывает правительственную власть принять безотлагательно самые решительные меры к поддержанию нравственного уровня молодого поколения», а в качестве конкретных мер представителям местных администраций предлагалось озаботиться «немедленным наведением порядка в поведении учащихся в публичных местах», установить «должное наблюдение за ученическими квартирами, устраняя возможность содержания таковых лицами нравственно неблагонадежными», и «своим личным влиянием и авторитетом» оказать «зависящее содействие к развитию и осуществлению всех условий, могущих восстановить и поддержать благонравие в этой среде» ${ }^{16}$. Таким образом, никаких новых указаний циркуляр не давал, но содержал просьбу сообщить о принятых мерах.

В последовавшем затем циркуляре Министерства народного просвещения, направленном в августе 1908 г. попечителю Западно-Сибирского учебного округа, как и попечителям дру-

\footnotetext{
${ }^{15}$ ГААК. Ф. 36. Оп. 2. Д. 47. Л. 22.

${ }^{16}$ Там же.
} 
гих учебных округов, отмечалось, что «благодаря содействию, на которое отныне с полным правом могут рассчитывать местные учебные начальства со стороны администрации, для них является возможным гораздо успешнее бороться с прискорбными явлениями», поэтому попечителям предлагалось незамедлительно обсудить меры, которые могут быть приняты на местах ${ }^{17}$.

Попечителем Западно-Сибирского учебного округа далее был отправлен собственный циркуляр руководителям учебных заведений округа с просьбой обсудить вопрос о мерах к поднятию нравственности среди учащихся на заседаниях педагогических советов ${ }^{18}$. При рассмотрении этого вопроса на заседании педсовета Омской учительской семинарии 2 сентября 1908 г. решено было еще больше усилить надзор за семинаристами, проверить ученические квартиры, устраивать для учащихся чтение статей и рефератов в памятные дни, «позаботиться об устройстве... в семинарии различных здоровых занятий, игр и развлечений», что должно было служить «средством отвлечения учащихся от развлечений порочных, от дурных мыслей и развития дурных наклонностей» ${ }^{19}$. Локальные акты свидетельствуют, что учебные заведения шли по привычному пути и занимались теми направлениями воспитательной работы, которые были описаны в действовавших правилах.

Следует отметить, что вопросы наблюдения за нравственностью учащихся и их поведением нашли отражение и в другом виде нормативных документов - постановлениях совещаний представителей учебных заведений отдельных городов по вопросу о внешкольном надзоре за воспитанниками. Данные совещания проводились под председательством высших чинов администрации региона и выносили решения, обязательные к исполнению учащимися не отдельного учебного заведения, а всех учебных заведений, располагавшихся на территории губернии или области. Так, на подобном совещании, проходившем в 1908 г. в Томске под председательством губернатора К. С. Нолькена, были выработаны основные положения правил внешкольного поведения учащихся, в число которых вошли обязательное ношение формы, посещение учащимися церкви, ограничение посещения театров и других увеселительных мест ${ }^{20}$. В Тюмени на совещании, проходившем в сентябре 1908 г. под председательством тобольского вице-губернатора Н. И. Гаврилова, учащимся было разрешено посещать театр, если там идут пьесы образовательного и воспитательного значения, но запрещались свидания с политическими заключенными ${ }^{21}$. В Омске на совещании директоров средних учебных заведений в сентябре 1911 г. под председательством губернатора обсуждался вопрос о желательности выработки общих мер надзора за поведением учащихся вне стен учебных заведений. По мнению участников, меры эти должны были способствовать повышению нравственности учащихся и побуждать их «быть всегда опрятно и по форме одетыми, не появляться на улицах позже известного часа, не позволять себе каких-либо грубых выходок по отношению прохожих, при встрече приветствовать начальствующих лиц края и членов педагогического персонала училища, не посещать трактиров, пивных, клубов» и прочих «публичных увеселительных мест» ${ }^{22}$. В феврале 1914 г. на таком же совещании было решено запретить учащейся молодежи посещать планировавшийся к открытию в Омске каток для катания на роликовых коньках в силу того, что в некоторых городах «скейтинг-ринки... приняли предосудительный в нравственном отношении характер» ${ }^{23}$.

В качестве альтернативы безнравственным, по мнению властей, развлечениям правительством предусматривалось вовлечение учащейся молодежи в юбилейные мероприятия военно-патриотического характера, что тоже определялось циркулярными распоряжениями. Так, в 1912 г. циркуляром Министерства народного просвещения было разрешено привлекать

\footnotetext{
${ }^{17}$ ГААК. Ф. 36. Оп. 2. Д. 47. Л. 21.

${ }^{18}$ Там же. Л. 19.

${ }^{19}$ ИсА. Ф. 115. Оп. 1. Д. 81. Л. 7-8.

${ }^{20}$ Сибирская жизнь. 1908. 28 сент.

${ }^{21}$ ГАТюмО. Ф. И-57. Оп. 1. Д. 194. Л. 136-139.

${ }^{22}$ ИсА. Ф. 64. Оп. 1. Д. 1. Л. 10.

${ }^{23}$ Там же. Ф. 32. Оп. 1. Д. 69. Л. 8-9.
} 
учащихся к празднованию 100-летнего юбилея Отечественной войны, с целью «оказать чрезвычайно благотворительное влияние на подрастающее поколение, способствуя укреплению и развитию в нем любви и преданности к Родине» ${ }^{24}$. Циркуляром Министерства народного просвещения 1912 г. предписывалось начальству учебных заведений «тщательно подготовить учащихся к настоящему 300-летию царствования дома Романовых», чтобы «развить и укрепить безграничную, способную на великие дела и подвиги любовь к своим Верховным Повелителям» ${ }^{25}$. Все эти мероприятия должны были способствовать достижению основной цели осуществления нравственно-воспитательной работы в школе, обозначенной в документах учебных заведений следующим образом: «Вести воспитание детей в национальном духе, в духе беззаветной любви и преданности к обожаемому Государю Императору, к нашей общей великой Родине и Святой церкви православной, выработать у них чувство долга перед церковью, Царем и Родиной; приучить их к тому, что священнейшей обязанностью каждого гражданина является настойчивый труд» ${ }^{26}$.

Таким образом, анализ законодательства, определявшего постановку нравственного воспитания учащихся в учебных заведениях Российской империи второй половины XIX - начала XX в., свидетельствует о достаточно четко определенной в них цели педагогического воздействия и всесторонней регламентации основных направлений воспитательной работы. Вместе с тем циркулярные распоряжения Министерства народного просвещения, будучи обязательными к исполнению, нередко только обозначали существующую проблему, но не содержали механизма ее решения, передавая этот вопрос на уровень учебно-окружного начальства и руководства отдельных учебных заведений. Однако активное участие учащейся молодежи в революционных событиях начала XX в. ставит под сомнение эффективность принимаемых мер.

\section{Список сокращений}

ГААК $\quad-\quad$ Государственный архив Алтайского края

ГАИО $\quad-\quad$ Государственный архив Иркутской области

ГАКК $\quad-\quad$ Государственный архив Красноярского края

ГАТюмО - Государственный архив Тюменской области

ИсА $\quad-$ Исторический архив Омской области

\section{Список литературы}

1. Чумаков П. В. Педагогические подходы нравственного воспитания личности // Вестник Новосиб. гос. пед. ун-та. 2011. № 1. С. 7-13.

2. Ищенко О. В. Правила поведения учащихся в учебных заведениях Западной Сибири (последняя четверть XIX - начало XX в.) // Азиатская Россия во второй половине XIX начале XX в.: проблемы региональной истории: Сб. науч. ст., посвящ. 60-летию профессора, доктора исторических наук А. П. Толочко / Под ред. Ю. А. Сорокина. Омск: Изд-во Ом. гос. ун-та, 2008. С. 179-196.

3. Красняков Н. И. Имперский фактор в государственном управлении России XVIII - начала XX вв. М.: Nota Bene, 2011. 373 с.

4. Крапоткина И. Е. Казанский учебный округ в конце XIX - начале XX века. М.: ФЛИНТА; Наука, 2011. 160 с.

5. Михеева И. В. Нормативно-правовые акты министерств Российской империи // Историко-правовые проблемы: Новый ракурс. 2011. № 4-2. С. 207-217.

\footnotetext{
${ }^{24}$ ИсА. Ф. 32. Оп. 1. Д. 43. Л. 8.

${ }^{25}$ Там же. Ф. 270. Оп. 1. Д. 81. Л. 21.

${ }^{26}$ ГАКК. Ф. 855. Оп. 1. Д. 3. Л. 80.
} 
6. Иванова С. П. Формирование правового поведения учащихся в учебных заведениях России во второй половине XIX - начале XX в. // Вестник Православного Свято-Тихоновского гуманитарного университета. Серия 4: Педагогика. Психология. 2011. № 21. C. 47-53.

7. Перцев В. В. Дореволюционная гимназия как воспитательная система // Концепт. 2016. № 3. С. 41-45.

8. Спиридонова Н. Ю. Система правового регулирования отношений в сфере образования // Вестник Чуваш. гос. ун-та. 2014. № 3. С. 289-292.

9. Поликутина Н. В. Классный наставник: проблема взаимодействия семьи и школы в России во второй половине XIX века // Вестник ЛГУ им. А. С. Пушкина. 2009. № 3 (Педагогика). С. 125-138.

10. Слепенкова Е. А., Щетинина Н. П. Становление института классного наставника в России во второй половине XIX - начале XX в. // Вестник Мининского университета. 2015. № 1 (9). С. 22-26.

11. Ватник Н. С. «Огарки»: мифы и реалии гимназической среды 1907-1908 годов // Российская история. 2010. № 6. С. 97-105.

\section{References}

1. Chumakov P. V. Pedagogicheskie podhody nravstvennogo vospitaniya lichnosti [Pedagogical approaches of moral education of the individual]. Bulletin of the Novosibirsk State Pedagogical University. 2011, no. 1, pp. 7-13. (in Russ.)

2. Ishchenko O. V. Pravila povedeniya uchashchihsya v uchebnyh zavedeniyah Zapadnoj Sibiri (poslednyaya chetvert' XIX - nachalo XX v.) [Rules of behavior of students in educational institutions of Western Siberia (the last quarter of $19^{\text {th }}$ - early $20^{\text {th }}$ century)]. In: Aziatskaya Rossiya vo vtoroj polovine XIX - nachale XX v.: problemy regional'noj istorii [Asian Russia in the second half of $19^{\text {th }}$ - early $20^{\text {th }}$ century: problems of regional history]. Collection of scientific articles dedicated to the $60^{\text {th }}$ anniversary of Professor, Doctor of Historical Sciences A. P. Tolochko. Ed. by Yu. A. Sorokin. Omsk, Omsk State Uni. Press, 2008, pp. 179-196. (in Russ.)

3. Krasnyakov N. I. Imperskij faktor $\mathrm{v}$ gosudarstvennom upravlenii Rossii XVIII - nachala XX v. [The imperial factor in public administration of Russia $18^{\text {th }}-$ early $20^{\text {th }}$ century]. Moscow, Nota Bene, 2011, 373 p. (in Russ.)

4. Krapotkina I. E. Kazanskij uchebnyj okrug v kontse XIX - nachale XX veka [Kazan educational district at the end of $19^{\text {th }}$ - early $20^{\text {th }}$ century]. Moscow, FLINTA, Nauka, 2011, 160 p. (in Russ.)

5. Mikheeva I. V. Normativno-pravovye akty ministerstv Rossijskoj imperii [Normative legal acts of the ministries of the Russian Empire]. History of Legal Problems: A New Perspective, 2011, no. 4-2, pp. 207-217. (in Russ.)

6. Ivanova S. P. Formirovanie pravovogo povedeniya uchashchikhsya v uchebnykh zavedeniyakh Rossii vo vtoroj polovine XIX - nachale XX v. [Formation of legal behavior of students in educational institutions of Russia in the second half of $19^{\text {th }}$ - early $20^{\text {th }}$ century]. Bulletin of the Orthodox St. Tikhon's Humanitarian University. Series 4: Pedagogy. Psychology, 2011, no. 21, pp. 47-53. (in Russ.)

7. Pertsev V. V. Dorevolyutsionnaya gimnaziya kak vospitatel'naya sistema [The pre-revolutionary school as the educational system]. Concept, 2016, no. 3, pp. 41-45. (in Russ.)

8. Spiridonova N. Yu. Sistema pravovogo regulirovaniya otnoshenij v sfere obrazovaniya [System of legal regulation of relations in the field of education]. Bulletin of the Chuvash State University, 2014, no. 3, pp. 289-292. (in Russ.)

9. Polikutina N. V. Klassnyj nastavnik: problema vzaimodejstviya sem'i i shkoly v Rossii vo vtoroj polovine XIX veka [Cool mentor: the problem of the interaction of family and school in 
Russia in the second half of the $19^{\text {th }}$ century]. Bulletin of the LSU named after A. S. Pushkin, 2009, no. 3 (Pedagogy), pp. 125-138. (in Russ.)

10. Slepenkova E. A., Shchetinina N. P. Stanovlenie instituta klassnogo nastavnika v Rossii vo vtoroj polovine XIX - nachale XX v. [The formation of the institute of a class mentor in Russia in the second half of $19^{\text {th }}$ - early $20^{\text {th }}$ century]. Bulletin of the Minin University, 2015, no. 1 (9), pp. 22-26. (in Russ.)

11. Vatnik N. S. "Ogarki”: mify i realii gimnazicheskoj sredy 1907-1908 godov ["Ogarki”: myths and realities of the gymnasium environment of 1907-1908]. Russian History, 2010, no. 6, pp. 97-105. (in Russ.)

\section{Информация об авторе}

Ищенко Оксана Владимировна, доктор исторических наук, доцент, профессор кафедры государственного и муниципального управления и управления персоналом, Сургутский государственный университет

SPIN 7193-6082

\section{Information about the Author}

Oksana V. Ishchenko, Doctor of Sciences (History), Associate Professor, Professor of the Department of State, Municipal and Personal Management, Surgut State University

SPIN 7193-6082

Статья поступила в редакиию 20.09.2021;

одобрена после рецензирования 01.11.2021; принята к публикации 01.11.2021

The article was submitted 20.09.2021;

approved after reviewing 01.11.2021; accepted for publication 01.11.2021 